\title{
Fixed-term contracts
}

\section{Are fixed-term contracts a stepping stone to a permanent job or a dead end?}

Keywords: fixed-term contracts, segmentation, employment, flexibility, employee screening, dual labor market

\section{ELEVATOR PITCH}

Fixed-term contracts have become a major form of employment in Europe. Available evidence about whether temporary jobs are a stepping stone to a permanent employment or are a dead end is mixed. The usefulness of these jobs depends on the institutional and economic environment. Fixed-term contracts can be a pathway from unemployment to employment, but their potential as a stepping stone to permanent employment is undercut if there is a strong degree of segmentation in labor markets. If that is the case, the labor flexibility motive of employers ends up dominating the screening function in offering a fixed-term contract.

\section{KEY FINDINGS}

\section{Pros}

๑ Introducing fixed-term contracts can create additional job opportunities for labor market entrants and reduce unemployment.

๑ Fixed-term contracts allow for the screening of workers in the context of strict dismissal protection.

๑ Under specific conditions, fixed-term contracts can be effective stepping stones to permanent employment.

† Fixed-term contracts are most effective in paving the way to stable employment if combined with training.
Share of fixed-term contracts in total employment (\%)

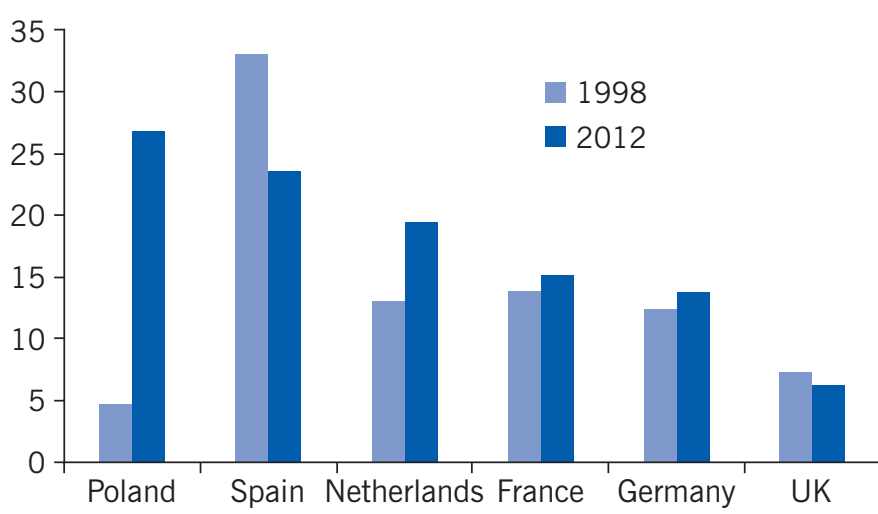

Source: Based on Figure 2.

\section{Cons}

- In a system with strict employment protection for open-ended contracts, the liberalization of fixedterm contracts can lead to a severe dualization of the labor market. A dual labor market effectively reduces employers' willingness to hire on a permanent basis.

- Fixed-term contracts can be associated with low productivity jobs and a significant wage gap

- In severely segmented labor markets, fixed-term contracts tend to be associated with alternating periods of temporary employment and phases of unemployment.

\section{AUTHOR'S MAIN MESSAGE}

There is no consistent evidence about whether fixed-term contracts are a stepping stone to permanent employment or a dead end. The role of temporary jobs depends on the institutional and economic environment. Fixed-term contracts can be pathways from unemployment to employment in particular for labor market entrants such as young people, but their potential as a stepping stone to permanent employment is undercut if an area of temporary jobs with high turnover emerges, contributing to a severely segmented labor market. Available evidence calls for reforms to ease the regulatory divide in national labor markets and/or to strengthen the vocational training content during fixed-term jobs, in particular when offered to young people. 


\section{MOTIVATION}

Over recent decades, many countries, particularly in Europe, have faced the problem of high and persistent unemployment as well as stagnating job creation. Labor market rigidities caused by high levels of employment protection are considered one major cause of this problem, both by academic experts and policy makers. This is particularly relevant in countries where permanent, open-ended contracts are protected by relatively strict rules against individual dismissal [1]. This represents a major obstacle to the dynamic development of employment. It stands in the way of providing young labor market entrants, unemployed or inactive people with better access to jobs. While employment protection for permanent jobs has proven quite difficult to change, mainly for political reasons, many countries have liberalized or deregulated fixed-term contracts (see Figure 1). This was expected to trigger additional job creation and better employment prospects for labor market "outsiders." Fixed-term contracts have now become a major segment of total employment (see Figure 2). The basic idea, however, is that fixed-term contracts act as stepping stones in a dual sense: First, they are supposed to ease the transition from unemployment, inactivity or education to a (temporary) job, and second, to increase the chance of a successful movement from a fixed-term to a permanent job.

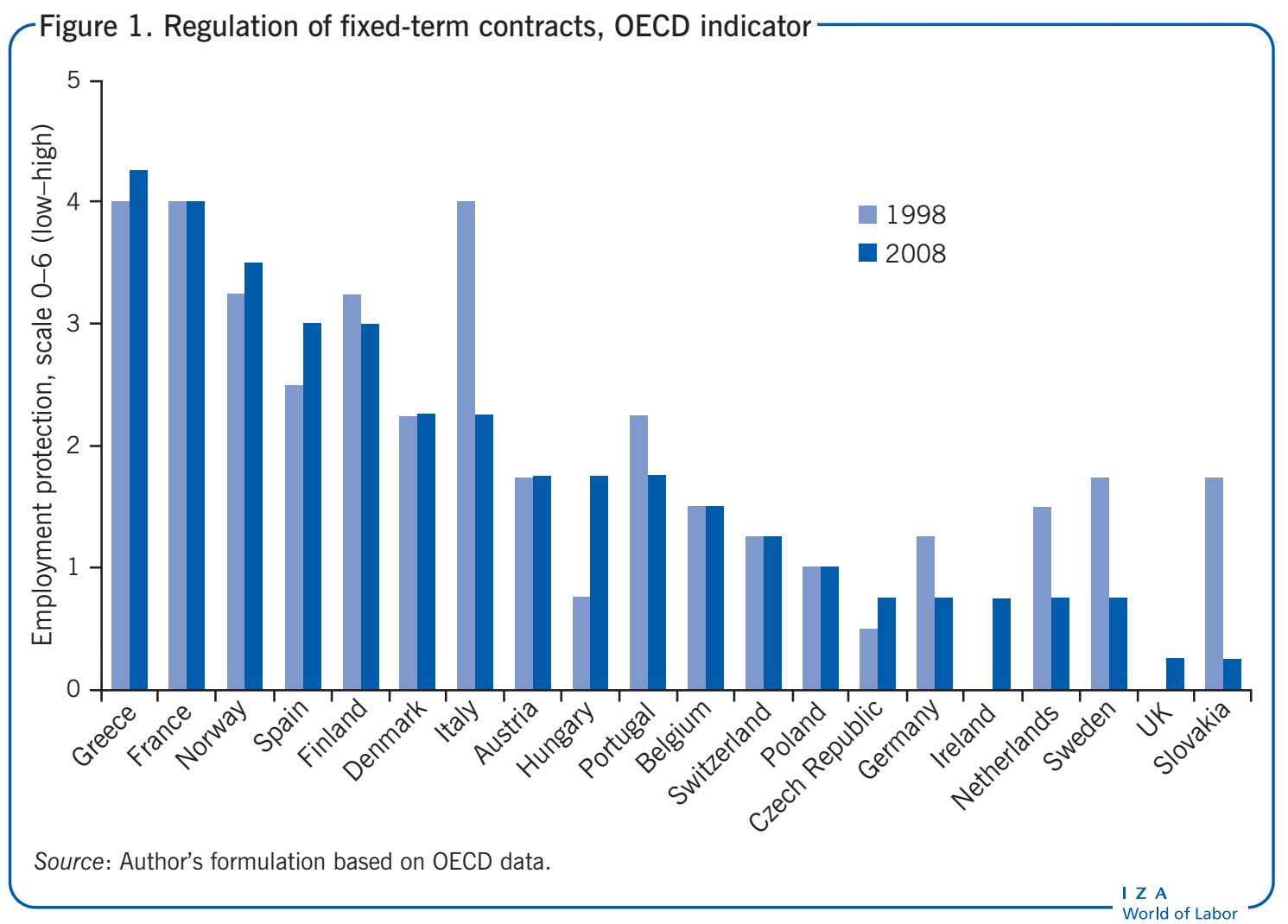

\section{DISCUSSION OF PROS AND CONS}

Fixed-term contracts were introduced in order to make hiring easier compared to offering only permanent contracts. This is especially relevant in countries with strict 


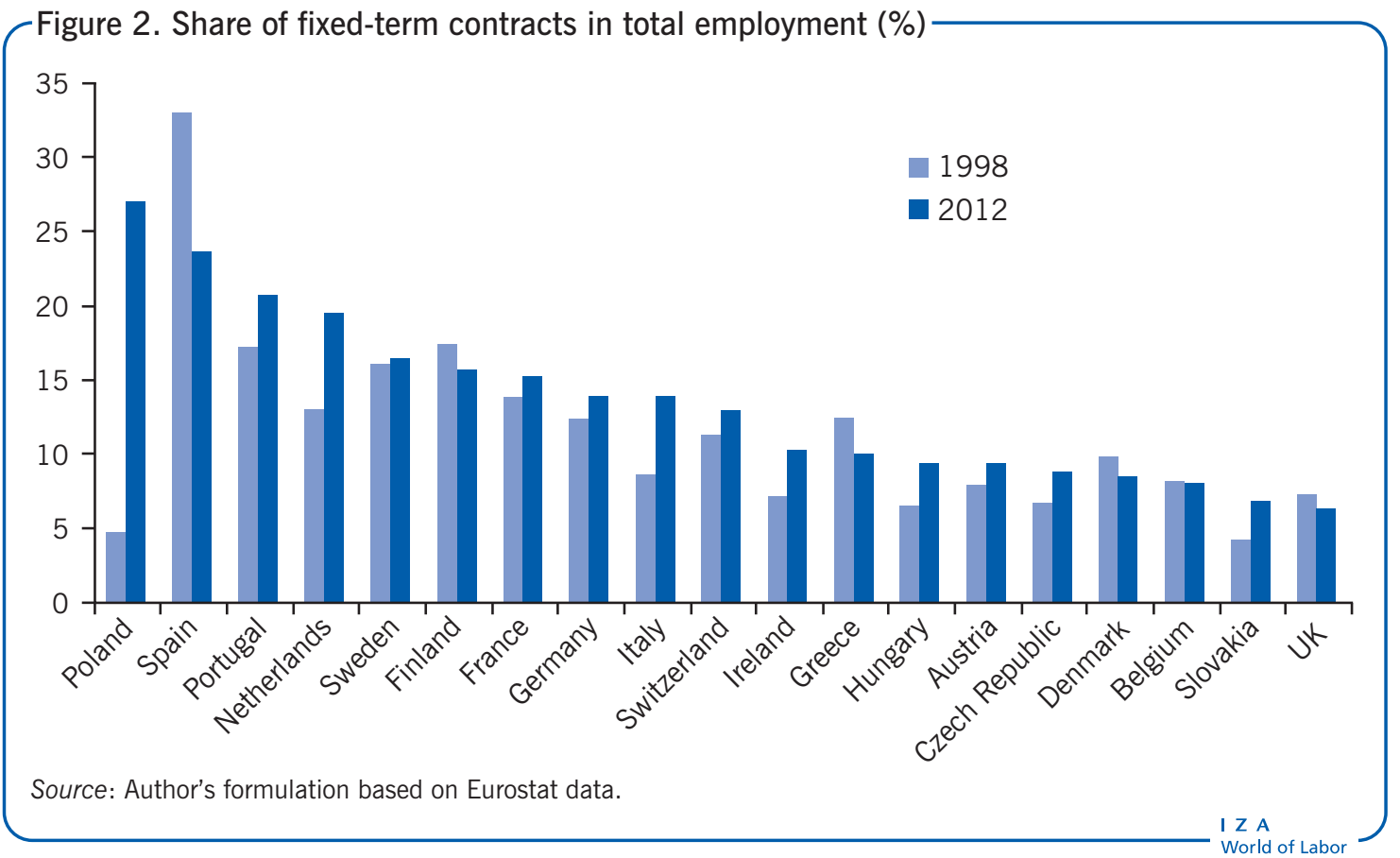

protections against individual dismissal. In addition, given that in most countries firing costs on open-ended contracts are non-negligible, there is a need for temporary or fixed-term contracts. These contracts are designed to reduce unemployment and create additional job opportunities, as well as providing a realistic prospect of being subsequently offered a permanent position.

Fixed-term contracts provide an extended probationary period or screening device for those who otherwise have difficulty entering the labor market. The basic idea is that at least good matches can subsequently be converted into permanent jobs (the stepping stone hypothesis).

This is particularly relevant in a country with strong employment protection for permanent jobs. The underlying idea in fixed-term contracts in such countries is for suitable screening to take place for employers and employees during an initial temporary employment period and thus to lessen the risk of a mismatch.

However, under such a regime, employers may also change their recruiting behavior and even their production model. Indeed, they might become more reluctant to hire people for open-ended contracts as soon as the option is available to use the flexible employment alternatives to create a segment of low-productivity, entry-level jobs with high turnover rates [2]. Hence, fixed-term contracts can in fact become dead-end jobs, thus creating a large share of temporary contract work. If that happens, it leads to a deep dualization or segmentation of labor markets, to the detriment of those who were originally the target group to benefit (entrapment hypothesis).

However, fixed-term contracts also have a buffer function in cases of cyclical and seasonal fluctuations. In such a situation, fixed-term contracts are not used as a screening device, but to adjust employment to fluctuations in demand. 
One way to study this empirically real-life effect of fixed-term contracts is to compare the careers of labor market entrants or the unemployed who take up a fixed-term contract to similar workers who do not take up that option. Another way is to compare labor market dynamics in a situation before and after the introduction or liberalization of fixed-term contracts.

In either case, if fixed-term contracts indeed are an effective stepping stone, then more of the people with a fixed-term contract status would gain access to permanent employment than people who did not opt for a fixed-term phase. In contrast, the stepping stone hypothesis would need to be rejected if one cannot observe a higher frequency of obtaining an open-ended contract. To be sure, frequent spells of fixedterm employment or cycling between temporary jobs and unemployment is not the outcome intended with the introduction of fixed-duration contracts.

Empirical research into the careers of workers on fixed-term jobs requires data that cover job characteristics (occupation, sector, firm size, training), individual characteristics (age, education, gender) and macroeconomic background variables (GDP growth, unemployment rates). It also requires having a longitudinal dimension, either with repeated observations of individuals or retrospective information in order to ensure that the status of individuals can be tracked over time.

A vast body of empirical research investigating whether, to what extent and under which conditions fixed-term contracts really constitute a stepping stone for those trying to enter the labor market has emerged over the years. There is a whole strand of literature covering mostly those countries where a notable liberalization and subsequent expansion of fixed-term contracts have occurred (e.g. France, Italy, Spain, Portugal, the Netherlands or Germany). However, there are also comparative studies and single country analyses covering less heavily regulated labor markets such as the UK.

\section{Key findings and discussion}

\section{France}

The introduction of fixed-term contracts in a highly regulated labor market such as France can have ambiguous results in practice, despite being aimed at reducing notoriously high youth unemployment [2]. French survey and panel data from 1983 to 2000 showed that the labor market for young labor market entrants was particularly affected. The share of fixed-term contracts increased heavily, while ever fewer young people were employed on a permanent basis. Unemployment remained rather constant over time. While the transition from unemployment to employment became easier for the broader population in the 1980s, the situation became actually more difficult for young people in the 1980s. Thus, there was no clear positive effect on youth unemployment. Both sub-periods-the 1980s and the 1990s-saw a decrease in permanent hiring for young people, lower rates of transition from fixed-term to permanent contracts and more young people remaining in temporary jobs. Furthermore, the 1990s were also characterized by a longer transition period from fixed-term to permanent employment, although that period was a little shorter 
compared to the transition from actual unemployment to permanent jobs. In addition, there was a growing wage gap between fixed-term and permanent jobs, hinting at the emergence of a segment of low-productivity jobs.

\section{Italy}

Italian panel data, allowing for different types of transitions on the labor market with a more long-term perspective allowing for more than one episode of fixed-term employment, found that a transition from temporary to permanent employment is more probable with increased contract duration [3]. However, multiple repeated fixed-term contracts seem to be detrimental to such a transition. This implies that fixed-term contracts are most problematic if repeated for a longer period of time. If that happens, temporary workers become trapped in a vulnerable situation, whereas good matches are promoted to a permanent contract at some point in time.

Similarly, employer-employee panel data were used to show that the type of temporary contract makes a difference regarding the stepping stone potential in the case of Italy [4]. In line with findings from other countries, they find that temporary jobs can improve the chance of transition to permanent employment compared to being or staying unemployed. However, the transition period tends to be quite long in the Italian case, with repeated temporary employment spells. There is some evidence of temporary jobs being used to cut labor costs and hence the creation of a trap from the employee's vantage point (entrapment hypothesis). Furthermore, contracts with a strong training component are more conducive to successful transitions, whereas freelance jobs and fixed-term contracts heavily subsidized by the government offer few opportunities. Moreover, if the transferable training content is limited, transitions to permanent positions with other employers are found to be rather difficult. This study emphasizes the importance of a closer look at institutional features of different types of temporary jobs.

\section{Spain}

The Spanish labor market has one of the highest rates of fixed-term contracts within the EU. Around $90 \%$ of all entries into employment start as fixed-term contracts. Fixedterm contracts are more a trap than a bridge, because the fixed-term employed are either stuck in fixed-term employment or, more frequently, become either unemployed or self-employed rather than employed on a permanent basis. Given that conversion rates are low, the evidence points to a severe segmentation of the Spanish labor market. Hence, it seems fair to argue that fixed-term contracts probably fostered employment growth in the case of Spain. However, the segmentation of the labor market brings with it a significant number of downsides. These include lower investment in human capital, higher wage pressure, a more unequal distribution of unemployment duration, lower mobility and fertility rates and larger wage dispersion [5].

\section{Portugal}

Investigating the labor turnover in Portugal caused by fixed-term contracts in 2012 a reform could be used as a quasi-experiment as the protection gap between open-ended 
and fixed-term contracts was widened for a group of firms yet remained the same for others. It was found that stricter dismissal protection on permanent contracts led to a more heavy reliance of employers on fixed-term contracts. This is associated with increasing worker turnover, such that the segmentation of the labor market between high turnover among temporary workers and low turnover experienced by permanent employees is aggravated [6].

Other studies show that a fixed-term contract significantly raises the probability that workers actually search for another job, thus indicating that fixed-term contracts are not only search devices for employers but also for workers. In a system with strong employment protection for permanent jobs, screening takes place on both sides during an initial temporary employment period, with the best matches tending to be converted into open-ended contracts. However, if a fixed-term job is experienced after a job loss in a later stage of a labor market career, the employment prospects of the workers are worse.

\section{Germany}

In Germany, the role of fixed-term contracts as screening devices act as an extended probationary period with a good chance for promotion to permanent employment [7]. This is particularly relevant for workers whose productivity and match with the job in question cannot be evaluated during the regular legal probation period of six months, e.g. with university graduates entering more complex jobs. Statistical matching showed that, apart from some early terminations of bad matches, job entries based on initial fixed-term employment are more stable than comparable entries via permanent contracts. In this context, fixed-term contracts have no negative impact on subsequent job stability, but can help to identify good matches between workers and jobs. Even so, in the German context, one can also observe that fixed-term contracts constitute a secondary labor market. As elsewhere, fixed-term workers encounter a high risk of repeated temporary employment. That is particularly true for those with low skills. However, highly skilled people with general skills also tend to be affected by fixed-term contracts, most notably in the public sector. Both high-skilled people and low-skilled labor market entrants in Germany pass through a phase of fixed-term employment more frequently than vocational trainees. Furthermore, unemployment rates of initial fixed-term workers and those taking up a permanent contract converge after five years. At least in the German case, there is no long-lasting negative effect of fixed-term contracts as entry jobs on later careers. In comparison with the screening mechanism, the trapping hypothesis seems to matter less in Germany.

\section{Netherlands}

A Dutch study analyzes the effect of temporary employment in a broader sense (involving fixed-term contracts, agency work and on-call contracts) on unemployment duration and the eventual transition to a permanent contract (including temporary jobs with a clear promise of being extended) [8]. A Dutch longitudinal data set reveals that temporary jobs tend to shorten unemployment duration, yet do not lead to a higher probability of being in permanent employment within a certain period of time, compared to labor market entrants without a temporary job experience. The stepping 
stone effect is found to be strongest concerning low skilled workers and male members of ethnic minorities as they benefit most from easier access to employment.

Furthermore, transition rates are relatively low during an initial phase of fixed-term employment. Moreover, wages in permanent jobs found via temporary jobs are higher than in cases where people take up a job directly out of an unemployment situation. One shortcoming of the study is that the authors treat different types of flexible employment together and do not identify the separate effect of fixed-term contracts as such which would allow for a clearer identification of the role of temporary jobs. The study suggests that, at least in the Dutch case, finding a permanent job on the basis of a fixed-term contract takes about as long as directly from unemployment. The advantage, of course, is that those people are at least not unemployed during this phase, but rather employed in temporary jobs.

\section{UK}

The UK has quite a flexible labor market. A seminal study used British Household Panel Survey data from the 1990s to examine the "dead end" vs. "stepping stone" hypothesis of temporary jobs [9]. For the period analysed, fixed-term contracts related to jobs that could in principle be permanent jobs (i.e., not casual or seasonal) indeed act as effective stepping stones. However, they are less attractive with regard to core parameters of job quality, such as wages, training or job satisfaction. These jobs are mostly taken up by young or older labor market entrants with specific human capital that can be developed further. While younger men had better transition probabilities than other groups, women rather than men are better equipped to catch up with respect to the wage level later on. According to this study, the stepping stone assumption seems to work in a labor market characterized by a lower level of employment protection for permanent workers.

\section{Poland}

Along with Spain, Poland has one of the highest shares of fixed-term workers in Europe. That phenomenon is particularly concentrated among young labor market entrants. Studies have examined the dynamics of entry and exit from fixed-term contracts by Polish school drop-outs, with a particular focus on the timing of exits from temporary employment. First, low skilled and generally educated youths are found to have a higher probability of entering fixed-term contracts, while vocational trainees have a higher chance of entering permanent jobs. However, the probability of moving from a fixed-term to a permanent contract does not diminish with tenure in temporary employment. Hence, the screening mechanism seems less pronounced in Poland. In addition, many fixed-term workers enter unemployment later on.

\section{Cross-country studies}

Comparative studies with a sample of European countries can be used to identify the crucial role that a whole range of labor market institutions and production regimes have on the frequency and stepping stone effect of fixed-term contracts. An analysis of the European Community Household Panel study showed the differences in transition 
rates from fixed-term to permanent contracts in France, West Germany, Denmark and the UK between 1995 and 2001 [10]. Significant differences in the transition probabilities were apparent, with the highest rates in Germany and the UK, followed by Denmark and France. These differences can be attributed to the institutional environment, which is not only constituted by employment protection legislation, but also by vocational training systems and national economic production models. Skill formation and the type of jobs clearly matter. The presence of a coordinated vocational training scheme can explain why fixed-term workers face better permanent job perspectives in Germany, where these jobs often work as probation periods. In contrast, the heavy labor market segmentation in France works to the detriment offixedterm employees there. Promotion to permanent jobs is difficult and unemployment spells are frequent. This is especially true for short-term, publicly subsidized fixed-term jobs. This study points to a broader institutional logic with regard to determining the actual role of fixed-term employment in different economies.

\section{LIMITATIONS AND GAPS}

Studies on the role of fixed-term contracts in European countries have yielded a vast variety of results. One difficulty in assessing the results is that many different methods have been used. Also, not all studies have analyzed the "pure" effect of fixed-term contracts as an alternative to other forms of entering the labour market or as an alternative to unemployment. Second, one has to bear in mind that research findings on fixed-term contracts not only interact with levels of dismissal protection of permanent jobs, but also with the regulation of many other forms of flexible employment. The latter include temporary agency work, freelance, and project-related self-employment or on-call or flexible part-time work. These alternative employment options influence the logic of fixed-term contracts in any specific national context.

The introduction of fixed-term contracts can also have effects on wages and productivity. Moreover, it can lead to an adjustment of the prevailing production regime in particular countries and sectors. Furthermore, concepts such as minimum wages, collective bargaining and subsidized fixed-term contracts-all implemented as part of active labor market policy-shape the role of temporary employment. Most important, one has to be aware of the role of vocational training and apprenticeships systems. Skill levels and work profiles obviously make a difference in facilitating or hampering the transition from education to work via fixed-term employment as an entry portal. Additionally, job stability by way of a permanent job after a fixed-term contract depends on a number of individual and contextual variables. Among others, factors such as a period of non-employment before taking up a fixed-term contract, low skills, working in an occupation requiring little skill or experience, working in a small firm as well as public sector employment may be correlated with a successful transition to a permanent job.

Hence, fixed-term contracts are ambiguous and their effects can hardly be assessed in a universal manner. Their role varies in accordance with the larger institutional environment and alternative channels of employment and flexibility. 


\section{SUMMARY AND POLICY ADVICE}

The empirical literature reviewed here suggests that the effect of an introduction of fixed-term contracts on unemployment is ambiguous. There is some evidence that fixed-term jobs can be a better alternative to unemployment, so that at least the first hurdle-from unemployment to paid work-can be overcome. However, a liberalization of fixed-term contracts in countries where the level of dismissal protection and other labour market regulations remains unchanged runs a high risk of creating a dual labor market. In such a regime, many fixed-term workers, in particular the young, are trapped in a secondary segment of flexible jobs. They do not have a substantial probability of moving beyond the second barrier, i.e., from a temporary to a permanent job.

Fixed-term employment may constitute an effective stepping stone for some categories of workers and jobs. This is mainly the case if they are used as a screening device for labor market entrants and allow for the accumulation of skills and work experience. In many cases, however, a deep segmentation of labor markets has emerged, as employers remain very reluctant to convert fixed-term jobs into permanent jobs. Overcoming an ingrained dualized labor market would work best if the regulatory gap between flexible temporary jobs and better protected permanent contracts is reduced or closed. That implies a convergence in the legal regulation of both forms of employment. However, national circumstances have to be taken into account. One concept that has received widespread attention in research and policy advice is the "single contract." Its distinction is that it replaces the old divide between fixed-term and open-ended contracts with a model that grants employment stability with increasing job tenure. Hence, the single contract provides a formally open-ended contract from the very first day of employment, but dismissal protection only grows over time. In such a system, dismissal protection implies a clear rule regarding severance pay while procedural requirements for lawful dismissal are simplified. Finally, combining fixedterm contracts with training by way of formal apprenticeships or other forms of systematic firm-related training would smooth the transition to permanent contracts.

\section{Acknowledgments}

The author thanks an anonymous referee and the IZA World of Labor editors for helpful suggestions on earlier drafts.

\section{Competing interests}

The IZA World of Labor project is committed to the IZA Guiding Principles of Research Integrity. The author declares to have observed these principles.

(C) Werner Eichhorst 


\section{REFERENCES}

\section{Further reading}

Boeri, T., and P. Garibaldi. "Two tier reforms of employment protection: A honeymoon effect?" The Economic Journal 117:521 (2007): 357-385.

D'Addio, A. C., and M. Rosholm. "Exits from temporary jobs in Europe: A competing risks analysis." Labour Economics 12:4 (2005): 449-468.

Boeri, T. "Institutional reforms and dualism in European labor markets." In: Ashenfelter, O., and D. Card (eds). Handbook of Labor Economics. Amsterdam: Elsevier, 1999; pp. 1173-1236.

\section{Key references}

[1] Cahuc, P., and F. Postel-Vinay. "Temporary jobs, employment protection and labor market performance." Labour Economics 9 (2002): 63-91.

[2] Blanchard, O., and A. Landier. "The perverse effects of partial labour market reform: Fixedterm contracts in France." The Economic Journal 112 (2002): 214-244.

[3] Gagliarducci, S. "The dynamics of repeated temporary jobs." Labour Economics 12 (2005): 429-448.

[4] Berton, F., F. Devicienti, and L. Pacelli. "Are temporary jobs a port of entry into permanent employment? Evidence from matched employer-employee data." International Journal of Manpower 32:8 (2011): 879-899.

[5] Amuedo-Dorantes, C. "Work transitions into and out of involuntary employment in a segmented market: Evidence from Spain." Industrial Labor Relations Review 53:2 (2000): 309-325.

[6] Centeno, M., and A. A. Novo. Excess Worker Turnover and Fixed-term Contracts: Causal Evidence in a Two-tier System. Bank of Portugal Working Paper 5/2012.

[7] Boockmann, B., and T. Hagen. "Fixed-term contracts as sorting mechanisms: Evidence from job durations in West Germany." Labour Economics 15 (2008): 984-1005.

[8] De Graaf-Zijl, M., G. J. van den Berg, and A. Heyma. "Stepping stones for the unemployed: The effect of temporary jobs on the duration until (regular) work." Journal of Population Economics 24:1 (2011): 107-139.

[9] Booth, A. L., M. Francesconi, and J. Frank. "Temporary jobs: Stepping stones or dead ends?" The Economic Journal 112 (2002): 189-213.

[10] Gash, V. "Bridge or trap? Temporary workers' transition to unemployment and to the standard employment contract." European Sociological Review 24:5 (2008): 651-668.

The full reference list for this article is available from the IZA World of Labor website (http://wol.iza.org/articles/fixed-term-contracts). 